\title{
Experiência literária e comunicação em Georges Bataille
}

\author{
Literary experience and communication in Georges Bataille
}

\section{Silvia Raimundi Ferreira}

Universidade Federal de Santa Maria - UFSM - Santa Maria - Rio Grande do Sul - Brasil

Resumo: O desejo de comunicar a experiência foi norteador da obra do escritor Georges Bataille; seu trabalho literário - tanto os ensaios filosóficos quanto os escritos eróticos - foi consagrado ao projeto de expressar, por meio da linguagem, aquilo que foge ao domínio da linguagem. Sua intenção de comunicar o real, de tocar com palavras os momentos definitivos da vida, aparece em seus textos no propósito explícito de levar o leitor a uma viagem ao extremo do possível, uma viagem que rompesse com os limites tradicionais do pensamento e da escrita, em uma comunicação que se daria via excesso. Georges Bataille enfrentou o abismo que se coloca na heterogenia dessas estruturas - experiência e linguagem, e, assim como outros autores, nos permite hoje, interrogar tanto o problema da representação e comunicação na linguagem literária quanto o mistério que envolve a capacidade da arte de conciliação desses elementos em uma obra que consegue transmitir aquilo que não está lá. Este artigo busca encontrar no romance Minha mãe elementos representativos dessa discussão, enlaçando-o com as noções de desejo e interdito propostos pela psicanálise.

Palavras-chave: Georges Bataille. Experiência. Comunicação. Psicanálise.

Abstract: The desire of communicating the experience guided Georges Bataille's oeuvre, his literary writing - both philosophical essays and erotic writings - was devoted using the project of expressing throughout language what is beyond the domain of language. His intention to communicate the real, the idea of touching with words the definitive moments of life, appears in his texts with the explicit purpose of taking the reader on a journey to the extreme, a journey that breaks the traditional limits of thinking and writing, in a communication that would happen through excess. Georges Bataille faced the chasm that lies in the heterogeneity of these structures - experience and language, and, like other authors, allows us today to question both the problem of representation and communication in literary language and the mystery surrounding the ability that art has to conciliate elements in a artwork that can convey what is not there. This article aims to search for meaningful elements of this discussion in the romance My Mother, approaching those exemples in a comparative way with the notions of desire and interdicted proposed by the psychoanalyst.

Keywords: Georges Bataille. Experience. Communication. Psychoanalysis. 


\section{Desejo e Interdito}

"O interdito diviniza aquilo a que ele proíbe o acesso" (BATAILLE, 1989, p. 18)

No prefácio de $A$ literatura e o Mal (1989), livro que reúne artigos de crítica literária escritos por Georges Bataille e publicados no jornal Critique, o sentido da literatura aparece relacionado à expressão de um tempo do qual o artista é contemporâneo, mas também expressão daquilo que esse tempo sufoca. Bataille se referiu a essas publicações como o "eco abafado" de uma geração que "despertou para a vida literária nos tumultos do surrealismo", ao mesmo tempo que lidava com os restos da Primeira Guerra (BATAILLE, 1989, p. 9). No pequeno texto que prefacia o livro, a palavra tumulto aparece inúmeras vezes, algumas relacionadas a algo específico da juventude e às sensações que transbordavam no período, outras ligada à própria essência da literatura em sua relação com o Mal, este compreendido não como oposição ao Bem, mas como o que se situa no domínio do trágico, da ambiguidade que funda as relações do homem com o desconhecido. Domínio que abraça as contradições, que compreende o íntimo acordo que se estabelece entre a lei e o interdito e que busca na dramatização uma forma de fusão desses elementos vistos, na maioria das vezes, como contraditórios.

Em A Literatura e o Mal, Georges Bataille aponta que o compromisso da literatura não é com o coletivo, mas com o instante no qual cada leitor pode deparar-se com uma experiência singular que excede a compreensão, experiência que não se apoia na razão, mas em estados (semelhantes a estados místicos) em que a solidão permite uma aproximação com a verdade humana. Essa noção de experiência será fundamental para a compreensão do projeto de comunicação literária presente na obra do autor.

Os "tumultos do espírito" e a "desmedida dos impulsos infantis" também fazem parte do universo proposto pela ficção escrita por Georges Bataille, textos nos quais os componentes morte e erotismo estão sempre presentes. O romance póstumo Minha mãe (1985) - que integraria uma tetralogia com Madame Edwarda, Divinus Deus e Paradoxo sobre o
Erotismo - narra, em primeira pessoa, a história de um filho que, aos dezessete anos, por ocasião da morte do pai, recebe da mãe esse pedido:

Gostaria - e esse foi o legado que, envenenando-se ela me deixou - que você me amasse até na morte. Da minha parte, amo você no instante da morte. Mas só quero o seu amor se você souber que sou repugnante e me amar sabendo disso (BATAILLE, 1985, p. 20).

Na narrativa, o filho, Pierre, compartilha com o leitor as lembranças da relação com sua mãe, desde a figura adorada pelo menino frágil, que a descreve como "aquela voz das doenças e das longas febres da minha infância" (BATAILLE, 1985, p. 11), período no qual a mãe era amada na mesma medida em que o pai era odiado, à transformação sofrida nessa relação com a morte do pai e com a nova configuração do amor que a mãe lhe impõe, onde o obsceno faz laço. Não sem sofrimento, o autor nos leva, passo a passo, a acompanhar o percurso trilhado pelo filho diante da tarefa assumida pela mãe de desencaminhá-lo. No trajeto, vemos o adolescente religioso, cuja figura da mãe confunde-se à figura de Deus, às voltas com um erotismo explícito que surge ainda na viagem que leva, mãe e filho, ao enterro do pai. A morte, em vez de trazer o alívio imaginado das longas noites de bebedeira do pai, revela a verdade sobre a obscenidade da mãe, assim como a necessidade de se fazer cúmplice do jogo materno. Réa, uma íntima amiga, é o elo que permite que mãe e filho sonhem experimentar, por meio dela, o desejo incestuoso. Afinal, para Pierre, é necessário ser digno de portar essa filiação: ser, segundo as palavras maternas, o filho dos bosques, filho da angústia, da raiva, "o filho libidinoso".

$\mathrm{Na}$ carta final, a mãe se despede:

Agora, tudo que está unido no mundo nos separa. Daqui para frente não poderíamos mais nos encontrar sem devassidão e, na devassidão, não devemos mais nos encontrar. $\mathrm{O}$ que une você a mim, o que me une a você está doravante unido até o intolerável e estamos separados pela profundeza do que nos une (BATAILLE, 1985, p. 95) 
No ato suicida a mãe reforça o laço incestuoso que propõe ao filho, justamente por se ausentar. $O$ que, segundo ela, os une, por manter-se irrealizável, conserva sua potência através dos tempos, e joga com a culpa do jovem, eternizando o desejo pela mãe.

\section{Alienação e separação}

"Ah, mamãe! que cumplicidade! (BATAILLE, 1985, p. 69)

Uma leitura crítica de Minha mãe parece ser indissociável do tema do sagrado - a mãe sagrada como ponto de intersecção entre o religioso e o erótico, entre o que aliena e o que separa. Bataille, nesse romance, desafia os tabus sociais mais primitivos ao mesmo tempo que revela a profunda relação que existe entre a instauração da lei, que o tabu interdita, e o surgimento do desejo. Os elementos culpa e transgressão caminham lado a lado no romance com a divinização da mãe pela criança enferma que deseja desesperadamente sua presença; da mesma forma, o convite incestuoso parece colocar em causa o desejo de completude entre mãe e filho, assim como o impossível desse desejo que a trama da narrativa vem a desvelar (retornaremos ao romance).

O psicanalista Sigmund Freud foi um dos primeiros pensadores a explorar o tema da interdição relacionando-o ao impossível. Em Mal-estar na Cultura, texto escrito em 1929 e publicado em 1930, Freud procura, nas origens da humanidade, aquilo que funda o mal-estar inerente à experiência humana. Para isso propõe uma análise tanto daquilo que está nas bases do pensamento religioso quanto na experiência infantil de desamparo e de angústia. No texto citado, o autor discorre sobre uma conversa que teria tido com o escritor Romain Rolland na qual este lhe interrogou sobre a existência de um sentimento de pertencimento ao mundo "[...] um sentimento que ele (Romain Rolland) gostaria de chamar de sensação de "eternidade", um sentimento como de algo sem limites, sem barreiras, 'oceânico', por assim dizer" (FREUD, 1930, p. 42). Freud, frente a esse questionamento assinala a equivocação da ideia que fazemos de nosso Eu como uma unidade independente e distinta do resto do mundo: as paixões amorosas e algumas patologias seriam o exemplo da fragilidade de nossas fronteiras. Mais do que isso, o autor lembra que o bebê, meses após seu nascimento, não se reconhece como unidade, ao contrário, precisa construir suas bordas corporais a partir do contato com o mundo externo, contato no qual ele expulsa o que lhe é desagradável e retém o prazeroso. Cito:

É desse modo, portanto, que o eu se separa do mundo exterior. Dito com mais exatidão: originalmente o eu contém tudo, mais tarde ele segrega de si o mundo exterior. O nosso atual sentimento do eu, portanto, é apenas um resíduo de um sentimento de grande abrangência - na verdade, um sentimento que abrangia tudo e correspondia a uma íntima ligação do eu com o ambiente (FREUD, 1930. p. 48).

O sentimento "oceânico" de pertencimento ao mundo seria correspondente a esse envolvimento primário: um resquício da formação do Eu que permanece na idade adulta. Da mesma forma, a religião estaria ligada à sensação infantil de desamparo, na medida em que o homem precisa supor um estado de existência completo, no qual não incidiria o mal-estar. Freud é taxativo em afirmar que o sonho de completude é uma ilusão, pois a passagem humana da natureza à cultura, passagem marcada pela entrada na linguagem, produz uma lacuna (um gap) impossível de ser recoberta.

Vinte anos após Mal-estar na Cultura, o psicanalista Jacques Lacan, em seminário sobre a ética da psicanálise, retoma as interrogações freudianas acerca do laço social e dos imperativos morais que o organizam, para pôr ênfase naquilo que ele denomina "universo da falta". Segundo o autor, toda a experiência moral, experiência que coloca o homem em uma certa relação com a lei, com um ideal de conduta - e por que não dizer com a culpa - estaria ancorada nessa impossibilidade de encontro com algo que corresponda ao anseio da criança. Esclarecemos: o processo de humanização produzido pela linguagem implica que a experiência humana de satisfação não está inscrita em nenhuma referência biológica, e sim suspensa a presença de um Outro que interprete as necessidades do bebê. Assim, as primeiras 
experiências de satisfação e frustração terão como base a leitura (operação de linguagem) que o outro materno faz dos sons e movimentos manifestados pela criança.

Essa falta originária (do objeto da satisfação) introduz, então, a criança no universo simbólico e aliena o seu gozo a essa mediação. A lei simbólica, introduzida pelo Outro, se inscreve equivocadamente para a criança, que está submetida à lei da linguagem, no registro de uma perda e não no da impossibilidade. Essa compreensão freudiana da insatisfação abre, de forma radical, para uma nova interpretação da dimensão ética do interdito: não se trata de uma questão moral, mas sim constitutiva. O objeto da satisfação é por sua natureza, um objeto perdido. Conforme Lacan: "O mundo freudiano, ou seja, o da nossa experiência comporta que é esse objeto, das $D^{\text {Ding }}{ }^{1}$, enquanto o Outro absoluto do sujeito que se trata de reencontrar". (LACAN, 1991, p. 69)

Ou ainda:

\begin{abstract}
O que encontramos na lei do incesto situa-se como tal no nível da relação inconsciente com das Ding, a Coisa. O desejo pela mãe não poderia ser satisfeito pois ele é o fim, o término, a abolição do mundo inteiro da demanda, que é o que estrutura mais profundamente 0 inconsciente do homem. É na própria medida em que a função do princípio do prazer é fazer com que o homem busque sempre aquilo que ele deve reencontrar, mas que não poderá atingir, que nesse ponto reside o essencial, esse móvel, essa relação que se chama a lei da interdição do incesto (LACAN, 1991, p. 87).
\end{abstract}

A lei da interdição do incesto, lei que fundamenta cultura é, conforme vem sendo desenvolvida, resultante da relação do homem com a linguagem (introduzida pela demanda), uma vez que é justamente a distância do sujeito com o objeto perdido que o permite desejar, em outras palavras: o desejo surge ali onde se coloca a interdição. Essa condição do desejo que implica em uma submissão à lei da castração é, também, perscrutada pelo autor a partir de referentes fundamentais em seu pensamento: os registros Real, Simbólico e Imaginário. Diz Lacan: "minha tese é de que a lei moral, [......], é aquilo por meio do qual, em nossa atividade enquanto estruturada pelo simbólico, se presentifica o real - o real enquanto tal, o peso do real" (LACAN, 1991, p. 31).

Ao associar o registro do Real à Coisa - esse Outro absoluto que se trata sempre de reencontrar e que aparece para o sujeito como proibido - Lacan situa as faces de júbilo e horror que a aproximação com o vazio originário comporta, direcionando o sujeito a uma conduta na qual o objeto de seu desejo seja mantido sempre à distância.

\section{Excesso e representação}

"Ensino a arte de transformar a angústia em delícia" (BATAILLE, 2016, p. 67)

Georges Bataille (1989, p. 22), em um de seus principais aforismos sobre a literatura, nos diz: "Sendo inorgânica, ela é irresponsável. [...] Ela pode dizer tudo". Nessa afirmação é possível vislumbrar o jogo que 0 autor estabelece entre a literatura e a transgressão; se há uma certa liberdade gozada pela literatura por seu caráter inorgânico também há uma provocação que remete ao tema da representação: o que seria dizer tudo?

A tentativa de leitura desse aforismo pode nos levar à compreensão - sempre parcial - que esse tudo, para Bataille, significa brincar com o perigo. É na literatura que 0 homem tem a possibilidade de aproximar-se daquilo que mais deseja e mais teme, pois a violência da paixão e o desejo dos corpos convocam a uma intensidade de sensações em que a felicidade se confunde com o sofrimento; escritos que convocam à desmedida dos impulsos infantis, em oposição ao pensamento racional do mundo adulto no qual o interesse comum e a consideração do futuro determinam as escolhas.

quanto à parte inassimilável da relação com o Outro, aquilo que é originalmente isolado pelo sujeito, expulso por ser estranho, hostil. É o fora-do-significado, anterior a todo recalque. Noção que será relacionada ao registro do Real.

\footnotetext{
1 Das Ding, termo alemão cuja tradução corresponde a "a Coisa", é uma expressão utilizada por Freud no texto "Projeto para uma Psicologia Científica" e retomada por Jacques Lacan para designar algo da relação da criança com o Outro. Corresponde tanto ao Outro como ao Bem supremo (noção aristotélica),
} 
Esse universo trágico - e infantil - que contraria às leis da razão, parece ser a pedra angular do pensamento do autor principalmente quando associado às noções de experiência e excesso. A busca pelo êxtase é uma constante dessa escrita que visa produzir no leitor sensações que escapem ao domínio do entendimento: ver o que não pode ser visto, escrever o que não pode ser escrito, são esses os impossíveis expressos na noção de experiência interior desenvolvida por Bataille. Seus relatos eróticos, seus poemas, têm, segundo ele, o objetivo de levar o leitor ao "ponto de excesso em que o coração falha" (BATAILLE,1978 p. 39), ponto em que o pensamento encontra o seu limite e abre à vertigem e à angústia. A experiência associada ao êxtase, aos momentos da vida que reúnem em si tanto o prazer extremo quanto o sofrimento, momentos que evocam, no ser, a sensação de dissolução, nos quais aquele que os vive deve, justamente, faltar. Como diz o autor: "A experiência é a colocação em questão (à prova), na febre e na angústia, daquilo que um homem sabe do fato de ser" (BATAILLE, 2016a, p. 34).

A busca por essa forma de experiência em Bataille é um trabalho que se dá sob um fundo de ausência (ou de vazio) que a prática da letra permite acessar:

\author{
"[...] palavras que sufocam, \\ me deixem, \\ me soltem, \\ tenho sede \\ de outra coisa (BATAILLE, 2016, p. 91).
}

Não admitir o reinado das palavras, ser mais que um instrumento das palavras, ser além delas, apesar delas, não o puro, mas o primordial, aquele que havia no encontro com a primeira representação. No livro $A$ experiência interior (2016) o autor questiona uma forma de trabalho com o discurso que visa afastar o homem de "sua única verdade", a de ser uma "súplica sem resposta" (BATAILLE, 2016, p. 44). Palavras "que só servem para fugir" coabitam com uma outra forma de trabalho com as palavras ligadas à dramatização e à possibilidade de encontro com um mais além delas mesmas:
É por meio de uma cessação íntima de toda e qualquer operação intelectual que o espírito é posto a nu. Senão, o discurso o mantém no seu pequeno aperto. O discurso, se assim quiser, pode atiçar a tempestade; por mais que me esforce, ao pé do fogo o vento não pode me congelar. A diferença entre experiência interior e filosofia reside principalmente no fato de que, na experiência, o enunciado não é nada, é apenas um meio e, tanto quanto um meio, um obstáculo; o que conta não é mais o enunciado do vento, mas o vento (BATAILLE, 2016, p. 45).

O vento, não o enunciado do vento, diz respeito à capacidade da arte dramática de fazer calar em nós o discurso para que a experiência interior, aquela em que a linguagem se furta, possa se dar. Um cheiro, um gosto, a recordação de uma sensação que provoca a angústia e o êxtase - a infância reencontrada; são esses momentos vagos, fugidios, que o autor busca se aproximar para propor essa forma de comunicação que ele denomina: contágio. Essa é verdadeira potência da expressão dramática: a de comunicar algo que está além do enunciado e que expressa discursivamente o que é de um outro campo, um campo que excede ao discurso.

O erotismo é, então, um território privilegiado dessa forma de comunicação, na medida em que toca diretamente no domínio das sensações e que expressa esse ponto de dissolução do ser, ponto que quebra a imagem homogênea que o homem quer ter de si mesmo, expondo os heterogêneos de que somos constituídos: Real, Simbólico e Imaginário - na acepção de Jacques Lacan. A comunicação em Bataille é expressão desse enlace.

Em Minha mãe, o desejo do incesto é o desejo inalcançável, o que não se realiza nunca, por isso o pedido inicial já traz em si a presença da morte como única possibilidade de sustentação do impossível: "Gostaria - [...] que você me amasse até na morte. Da minha parte amo você no instante da morte" (BATAILLE, 1985, p.20). Instante e continuidade surgem como opostos que trabalham unidos no projeto de suspensão dos descontínuos: o instante, momento em que o "sujeito encontra seu ponto de ebulição" (ou de fragmentação, poderíamos dizer) para dissolver-se no outro, e a morte, a "indecência da morte", violência 
que interrompe o curso regular da vida, mas também negativo que funda a experiência humana:

A velhice renova o terror ao infinito. Ela reconduz o ser sem termo para o começo. $\mathrm{O}$ começo que à beira da tumba entrevejo é o porco que em mim nem a morte nem o insulto podem matar. O terror à beira da tumba é divino e mergulho no terror do qual nasci (BATAILLE, 1985, p. 9).

Nascimento, erotismo e morte, passagens vertiginosas em o vazio clama por alguma atribuição de sentido, mas o sentido é insuficiente, não recobre o mal-estar; se declarar culpado é, então, uma saída. Em Minha mãe a culpabilidade entre mãe e filho se dá no desafio à interdição, o incestuoso no livro é a manutenção da possibilidade da relação, que o ato sexual viria a pôr um fim. Ao não romper a barreira do interdito o desejo de continuidade se mantém, sendo que as mãos de Réa cumprem a função de ligação entre os dois, pois ela é tanto o veículo que os separa quanto o obstáculo que os mantém interligados.

Bataille compara o erotismo a um labirinto terrível, no qual aquele que se perde também é aquele que estremece. É esse labirinto que dá a seus escritos essa potência perturbadora que combina sagrado e profano, êxtase e pensamento. Ao comunicar a experiência através do texto literário Georges Bataille rompe com a distância que separa experiência e escrita, permitindo ao leitor uma espécie de contágio do vivido na realidade ou na imaginação do autor.

\section{Referências}

BATAILLE, Georges. O Erotismo. Porto Alegre: LP\&M, 1987.

$$
\text { A literatura e o mal. Porto }
$$

Alegre: LP\&M: 1989.

Brasiliense, 1985.

. Madame Edwarda, O Morto, História do Olho. Lisboa: Edições A. Ramos, 1978.

A experiência interior: seguida de Método de Meditação e Postscriptum 1953. Belo Horizonte:Autêntica, 2016.

UFMG, 2015.

. Poemas. Belo Horizonte: Editora

BLANCHOT, Maurice. A Conversa Infinita 2: a experiência limite. São Paulo: Escuta, 2007.

FREUD, Sigmund. O mal-estar na cultura. Porto Alegre: LP\&M, 2010.

LACAN, Jacques. Seminário, livro 7: a ética da psicanálise. Rio de Janeiro: Zahar, 2008.

\section{COMO CITAR ESSE ARTIGO}

FERREIRA, Silvia Raimundi. Experiência literária e comunicação em Georges Bataille. Signo, Santa Cruz do Sul,

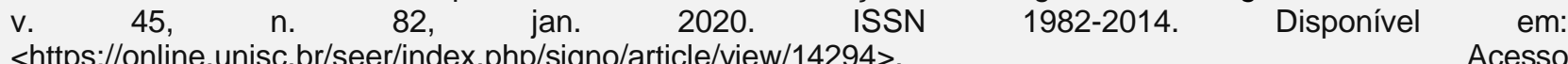
em:_ doi:https://doi.org/10.17058/signo.v45i82.14294. 